\title{
Seed Development in Lesquerella fendleri (L.)
}

\author{
Grace Q. Chen ${ }^{1}$, Louisa Vang, and Jiann-Tsyh Lin \\ USDA-ARS, Western Regional Research Center, Crop Improvement and \\ Utilization, 800 Buchanan Street, Albany, CA 95710
}

Additional index words. Lesquerella fendleri, seed development, morphology, seed weight, oil content, protein profile, seed germination

\begin{abstract}
The morphological, physiological, and biochemical changes during seed development of Lesquerella fendleri were investigated from 7 days after pollination (DAP) to desiccation. The entire course of seed development lasted $\approx 49$ days and it can be divided into seven sequential stages (I to VII). During the early stages (I to III, 7 to 21 DAP), seed grew rapidly, showing a dramatic increase in size and fresh weight. They contained $\approx 75 \%$ water. During midmaturation stages (IV to V, 28 to 35 DAP), storage lipids, proteins, and other components of dry weights accumulated at maximum rates. The accumulation curves followed a sigmoidal pattern during seed development. As a result of water loss, fresh weight dropped significantly when seed progressed to latematuration/desiccation stages (VI to VII, 42 to 49 DAP). The size of the seed decreased slightly and the color changed from green to orange-brown. Seed proteins were also analyzed using SDS-PAGE. Proteins with high molecular weights were prominent in developing seed at early stages (I to III). At Stage IV (28 DAP), proteins with low molecular weight appeared, whereas the high-molecular-weight proteins decreased in proportion. These low-molecular-weight proteins became predominant throughout the remaining stages of seed development. Forty-seven percent of freshly harvested seed at 35 DAP were able to germinate after 7 days incubation. The germination percentage increased to a maximum of $95 \%$ at 42 DAP after 7 days incubation. The relationships among seed morphology, reserve synthesis, and germination are discussed.
\end{abstract}

The conventional source of hydroxyl fatty acid is from castor oil, which contains $90 \%$ ricinoleate $(\mathrm{C} 18: 1 \mathrm{OH})$. Ricinoleate and its derivatives are used as raw materials for numerous industrial products such as lubricants, plasticizers, and surfactants (Caupin, 1997). The production of castor oil, however, is hampered by the presence of the toxin ricin and hyperallergic $2 \mathrm{~S}$ albumins in its seed. Lesquerella fendleri (L.) (Brassicaceae), being developed as a new industrial oilseed crop in the southwestern region of the United States, is valued for its unusual hydroxy fatty acid (HFA). The HFA in L. fendleri was named lesquerolic acid $(\mathrm{C} 20: 1 \mathrm{OH})$ (Smith et al., 1961), which is derived by a two-carbon elongation of ricinoleate (Engeseth and Stymne, 1996; Reed et al., 1997). Lesquerella oil represents an alternative to castor oil as a source of HFA. Besides the HFA, there are several coproducts from $L$. fendleri. For example, the seed meal after oil extraction is high in protein and the amino acid lysine and could be

Received for publication 23 Apr. 2009. Accepted for publication 27 May 2009.

The work was supported by the USDA-ARS Current Research Information System (CRIS) Project 5325-2100-012-00D.

We thank Debbie Laudencia-Chingcuanco and Niu Dong for critical reading of the manuscript. We also thank Frances DuPont for helpful discussion on protein analysis as well as for critical reading of the manuscript. Thanks are extended to Dr. David Dierig for kindly supplying the $L$. fendleri seed.

${ }^{1}$ To whom reprint requests should be addressed; e-mail grace.chen@ars.usda.gov. used as livestock feed (Carlson et al., 1990; $\mathrm{Wu}$ and Hojilla-Evangelista, 2005). Gums from the seedcoat and seed meal could be used as thickening or gelling agents in food and pharmaceutical products (Abbott et al., 1994; Harry-O'kuru et al., 1999; Holser et al., 2000; Wu and Abbott, 1996, 1999).

Knowledge of seed development is essential to successful seed production and crop improvement. This work gives a broad description of $L$. fendleri seed development from fertilization to desiccation. Data presented include: temporal details of morphological (seed size and color), physiological (fresh weight, dry weight, and germination), and biochemical (storage oil and protein) changes in developing seed at various stages.

\section{Materials and Methods}

Plant material and general growth conditions. L. fendleri seed, WCL-LY2 (Dierig et al., 2001), were germinated and grown in a greenhouse at temperatures between $28^{\circ} \mathrm{C}$ (day) and $18^{\circ} \mathrm{C}$ (night) with supplemental metal halide lighting providing a 15-h daylength $\left(1000\right.$ to $\left.1250 \mu \mathrm{mol} \cdot \mathrm{m}^{-2} \cdot \mathrm{s}^{-1}\right)$. Mature female flowers were individually hand-pollinated and tagged, and the tagging dates were recorded as $0 \mathrm{~d}$ after pollination (0 DAP). Silique were harvested at 7-d intervals from 7 DAP to 49 DAP. Because of the extremely small size and weight, seed were carefully dissected out of the silique and counted under an optical glass binocular magnifier. Seed images were taken under a Leica dissecting microscope (Leica micro- systems Ltd., CH-9435 Heerbrugg, Switzerland) equipped with a digital camera. Fresh weight was measured on 500-seed replicates for 7 and 14 DAP samples and 100-seed replicates for $21,28,35,42$, and 49 DAP samples. The same sets of seed samples were dried by vacuum centrifugation overnight at $50^{\circ} \mathrm{C}$ and weighed to calculate the dry weight and the water content.

Seed germination tests. Seed germination experiments were conducted with separate sets of seed. As a result of the limitation of seed numbers, germination tests were carried out on triplicates of 50 seed from Stage IV to VII (28 to 42 DAP) at $25{ }^{\circ} \mathrm{C}$ on $0.6 \%$ agar plate in dark. Seed germination was evaluated daily up to 1 week. Seed having a radical length greater than $0.5 \mathrm{~cm}$ in length were counted as germinated seed.

Lipid content measurements. Seed of each stage was overnight vacuum dried at $50{ }^{\circ} \mathrm{C}$ and ground, and triplicates were prepared by weighing $0.03 \mathrm{~g}$ of dried seed sample into 10 $\mathrm{mL}$ glass tubes. The lipids were extracted using $2 \mathrm{~mL}$ hexane/2-propanol (8:2) containing $50 \mu \mathrm{g} / \mathrm{mL}$ butylated hydroxytoluene to prevent oxidation during extraction. The extraction took place at $55^{\circ} \mathrm{C}$ for $30 \mathrm{~min}$ with shaking every $10 \mathrm{~min}$. The extracts were filtered and dried over sodium sulfate, and the solvent was evaporated under nitrogen. The lipid weight was determined gravimetrically. The nonlipid dry weight was obtained by subtracting the lipid from the seed dry weight.

Protein analyses. For seed protein analysis, sets of seed were dissected and frozen immediately in liquid nitrogen and stored at $-80{ }^{\circ} \mathrm{C}$. Seed were ground in liquid nitrogen and triplicates were prepared by weighing $0.03 \mathrm{~g}$ of fresh-ground seed sample into Eppendorf tubes containing $0.5 \mathrm{~mL}$ extraction buffer [50 mM Tris, $\mathrm{pH} 7.5 ; 2 \%$ sodium dodecyl sulfate (SDS), 25\% glycerol; 400 $\mathrm{mm}$ dithiothreitol]. The tubes were incubated at $70{ }^{\circ} \mathrm{C}$ for $10 \mathrm{~min}$ and then centrifuged at $16,000 \times g$ for $10 \mathrm{~min}$ at room temperature. Clear supernatant was taken by avoiding the precipitants and the top floating lipid layer. Protein content was quantified by using $10 \mu \mathrm{L}$ of the supernatant following a Bio-Rad Protein Assay Microassay Procedure (Bio-Rad, Hercules, CA). To examine protein profiles, $10 \mu \mathrm{g}$ of the protein was resolved on a $4 \%$ to $12 \%$ Bis-Tris NuPAGE gel with MES-SDS running buffer in the electrophoresis system (Invitrogen, Carlsbad, CA), and the gel was stained with the Coomassie Blue G-250 (BioRad) and dried using the DryEasy Mini-Gel Drying system (Invitrogen, Carlsbad, CA) according to the manufacturer's instructions.

\section{Results}

\section{Stages of seed development}

In L. fendleri, flowering progresses from the base of inflorescence to the apex and seed are produced sequentially. To obtain seed having at the same developmental age, mature flower buds were manually pollinated and dated. Morphological and physiological changes in the developing seed 
were examined from 7 DAP up to maturity. We found that the entire course of seed development lasts $\approx 49 \mathrm{~d}$ (Fig. 1). Three major physiological periods of seed development, characteristic of most seed plants, were also exhibited in L. fendleri. There was an early seed development period indicated by rapid increase in whole-seed fresh weight $(0$ to 21 DAP; Fig. 2A) followed by a midmaturation period indicated by a steady increase in dry weight (28 to 35 DAP; Fig. 2A) and then a late-maturation/desiccation period indicated by water loss (42 to 49 DAP; Figs. 2A and $2 \mathrm{C})$. These three periods were further subdivided into seven stages (I to VII). Figure 1 illustrates the size and color of the developing seed at each stage. Figure 2 shows the changes of fresh weight, dry weight, and water content during seed development.

Stages I to III. During this early seed development period, seed increased in size and gained fresh weight rapidly (Figs. 1 and 2A). The majority of the fresh weight was water, ranging from $71 \%$ to $75 \%$ (Fig. 2C). Seed were soft, ovoid, and translucent yellow in color (Stage I; 7 DAP). They turned to light green at Stages II and III (14 and 21 DAP; Fig. 1).

Stages IV to $V$. During this midmaturation period, seed continued to increase in size and fresh weight but more slowly than before. Eventually, seed reached a maximum size (Fig. 1) and a maximum fresh weight at Stage V (35 DAP; Fig. 2A). The seed dry weight also increased steadily and reached a plateau at Stage V (Fig. 2A). Despite the gain in seed weight, the water content declined from $71 \%$ at Stage III (21 DAP) to $46 \%$ at Stage V (35 DAP; Fig. 2C). Seed were nearly spherical at Stage IV (28 DAP) and became flattened at Stage V (35 DAP). Seed color remained green (Fig. 1).

Stages VI to VII. During this late-maturation/ desiccation period, seed had constant dry weight (Fig. 2A), but water content dropped dramatically from $46 \%$ at Stage V (35 DAP) to 5\% at Stage VII (49 DAP) (Fig. 2C). Desiccated seed weighed $\approx 66 \mathrm{mg}$ per 100 seed (Fig. $2 \mathrm{~A}$ ). They were reduced in size and remained flattened (42 to 49 DAP; Fig. 1). The color of seed was orange-brown at Stage VI (42 DAP; Fig. 1) and dark orange-brown at Stage VII (49 DAP; Fig. 1). We noted that silique were green during most stages of seed development and turned to greenish yellow at Stage VI and yellow at Stage VII.

\section{Changes in lipid content during seed development}

During the early seed development period up to 21 DAP (Stages I to III), the lipid content was $2.5 \%$ to $3.7 \%$ of dry weight (Fig. 2B). After Stage III, the lipid content increased quickly and reached $23.5 \%$ of dry weight at Stage V (35 DAP; Fig. 2B). During the late-maturation/desiccation period, the lipid content increased slightly to $25.7 \%$ and $27.6 \%$ at Stages VI (42 DAP) and VII (49 DAP), respectively (Fig. 2B).

\section{Changes in protein content and temporal pattern during seed development}

During the early seed developmental stages (Stages I to III, 7 to 21 DAP), protein content was between $5.8 \%$ and $8.7 \%$ of fresh weight (Fig. 3). The content increased quickly thereafter to $22.7 \%$ at Stage VI (42 DAP) and slowly increased to a maximum of 23.6\% at Stage VII (49 DAP; Fig. 3). Proteins with high molecular weight $(97,80,70,50$, $38,32,26$, and $23 \mathrm{kDa}$ ) predominated in seed at Stages I to III. These high-molecularweight bands faded at Stage IV and disappeared by Stage V (Fig. 4). Proteins with low molecular masses ( 35 to $30,23,15$, and 10 to $6 \mathrm{kDa}$ ) started to accumulate at Stage IV and became predominant at later stages of development (Stages V to VII; Fig. 4).

\section{Seed germination at the various stages of seed development}

Seed germination was tested from Stages IV to VII (Fig. 5). No germination was observed at Stage IV. Germination percentage increased sharply to $47 \%$ at Stage V (35 DAP) and reached a maximum of $95 \%$ at Stage VI (42 DAP) after $7 \mathrm{~d}$ incubation. Germination percentage decreased slightly to $89 \%$ when seed were fully desiccated at Stage VII (49 DAP).

\section{Discussion}

Seed development has three phases in most seed plants: early seed development, midmaturation, and late-maturation/desiccation (Baud et al., 2002). The identification of distinct morphological and physiological characteristics of these three phases is an important step in understanding seed development. In our study, early seed development in L. fendleri lasted 21 DAP. During that period, seed increased in size and fresh

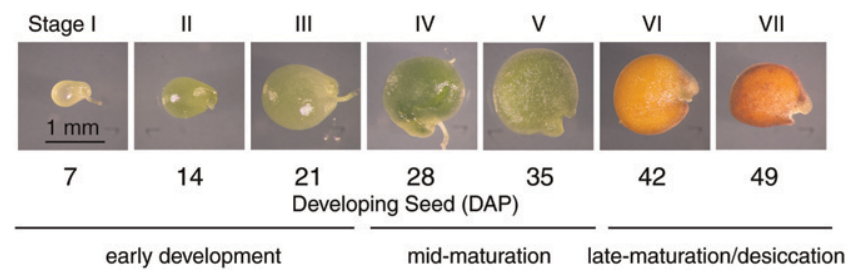

Fig. 1. The morphological changes of Lesquerella fendleri during seed development. Mature female flowers were individually hand-pollinated and tagged, and the tagging dates were recorded as $0 \mathrm{~d}$ after pollination (0 DAP). Silique were harvested at 7-d intervals from 7 DAP to 49 DAP. Seed were dissected out of the silique under an optical glass binocular magnifier. Seed images were taken under a Leica dissecting microscope equipped with a digital camera.

weight but without reserve synthesis. Water content was high ( $71 \%$ to $75 \%)$ and the lipid and protein contents were low, $2.3 \%$ to $3.7 \%$ and $1.7 \%$ to $2.7 \%$, respectively. When entering the maturation period, seed began to synthesize storage lipids and proteins and
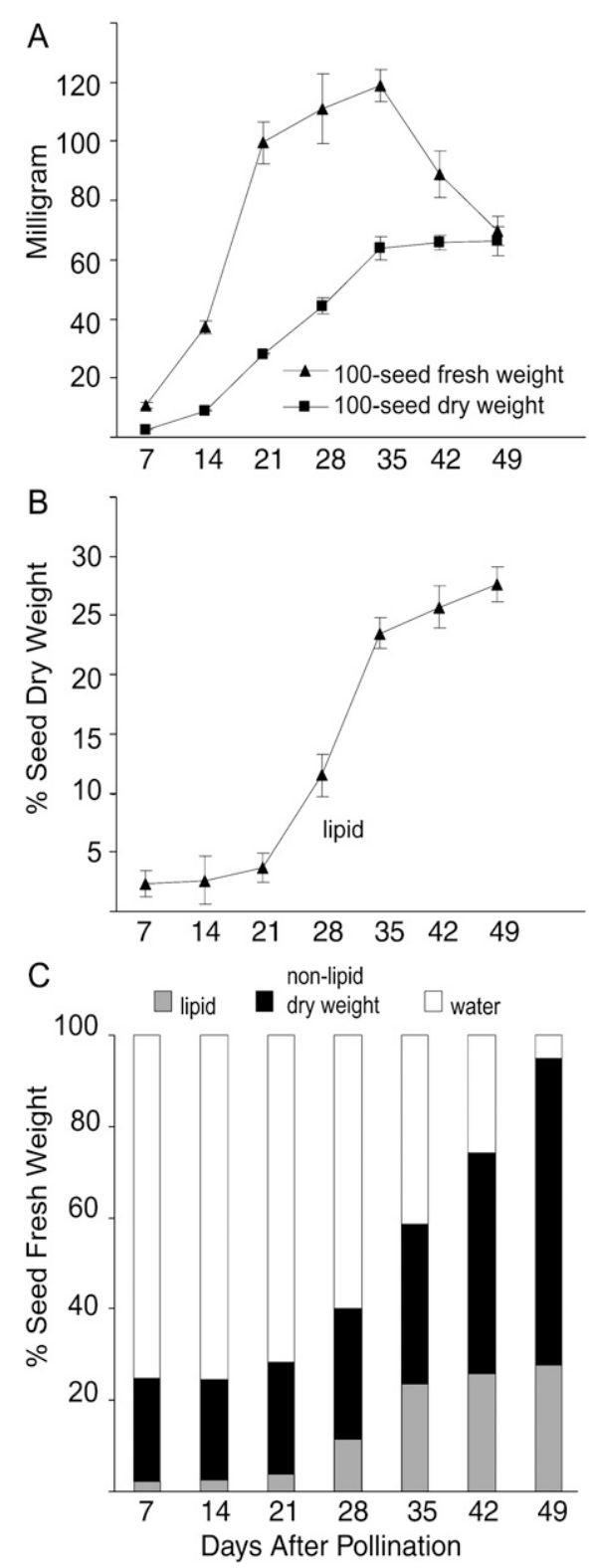

Fig. 2. The growth curves of seed development. Silique were harvested at 7-d intervals from 7 $\mathrm{d}$ after pollination (DAP) to 49 DAP. Seed were dissected out and counted under an optical glass binocular magnifier. Fresh weight was measured on 500-seed replicates for 7 and 14 DAP samples and 100-seed replicates for 21, $28,35,42$, and 49 DAP samples. The same sets of seed samples were dried by vacuum centrifugation over night at $50{ }^{\circ} \mathrm{C}$ and weighed to calculate the dry weight and the water content. (A) Changes of 100-seed fresh weight (closed triangles) and dry weight (closed squares). (B) Changes of lipid content. Each data point represents the mean \pm SD of triplicates. (C) Changes of lipids (gray bar), nonlipid dry weight (closed bar), and water content (open bar). Each point represents the mean of three measurements. 


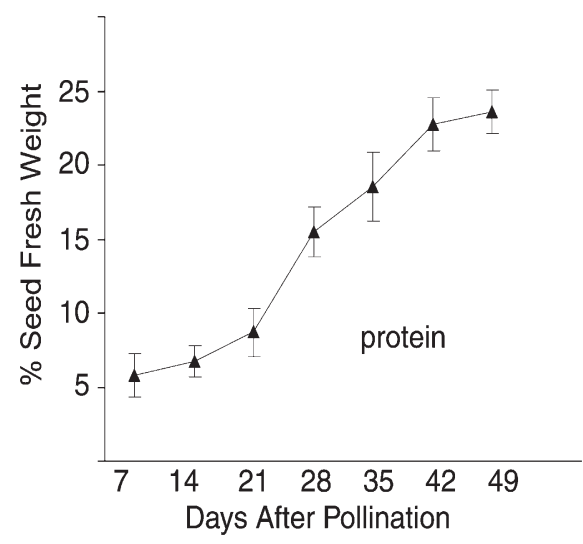

Fig. 3. Changes in protein content during seed development. Silique were harvested at 7-d intervals from $7 \mathrm{~d}$ after pollination (DAP) to 49 DAP. Seed were dissected and frozen immediately in liquid nitrogen. Each data point represents the mean \pm SD of triplicates of $0.03 \mathrm{~g}$ of fresh-ground seed sample in liquid nitrogen.

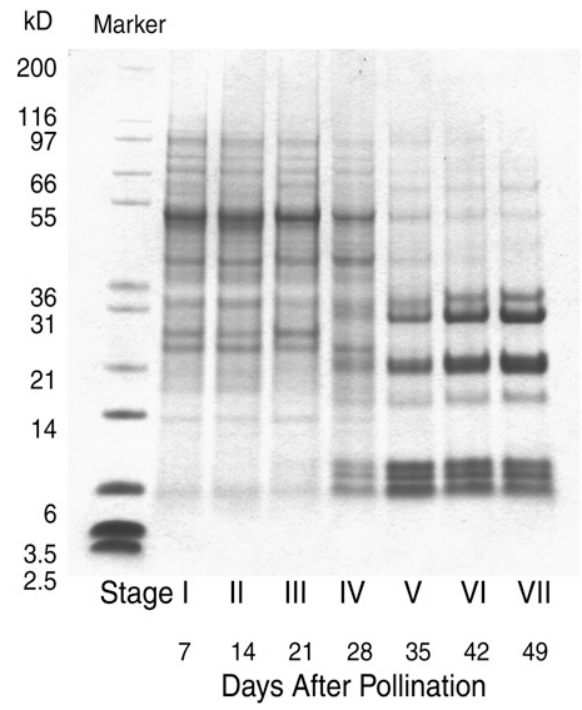

Fig. 4. The profile of protein pattern during seed development. Ten micrograms of the protein was resolved on a gel in the electrophoresis system, and the gel was stained with the Coomassie Blue-G250 and dried using the DryEasy Mini-Gel Drying system from Invitrogen.

kept the accumulation rate at a maximum. The overall temporal accumulation showed a sigmoid pattern similar to that of dry weight. At the end of midmaturation (35 DAP), seed reached their maximum size and maximum weight. The increase in seed fresh weight was the result of dry mass accumulation because the water content had already started to decline. After 35 DAP, seed entered a latematuration/desiccation period, during which the dry weight did not change but the water content declined dramatically from $46 \%$ to $5 \%$. The dehydration is an inherent phase of seed development (McIlrath et al., 1963), a sign of maximum maturity and onset of a quiescent state. The three major periods outlined by distinctive changes in fresh and dry

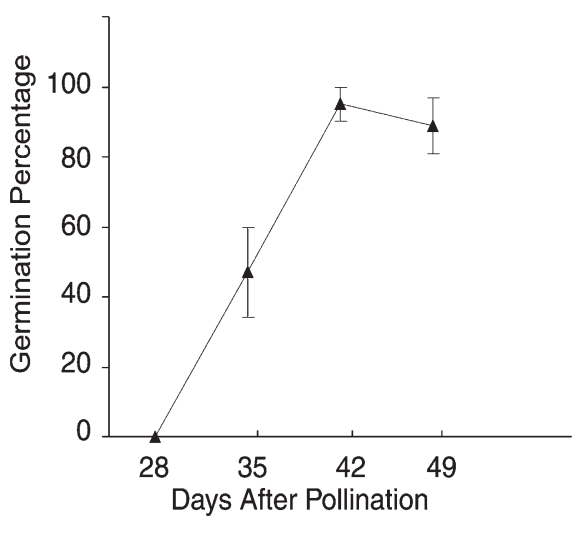

Fig. 5. Changes in germination percentage (\%) during seed development. Germination tests were carried out on triplicates of 50 seed from Stage IV to VII ( 28 to $42 \mathrm{~d}$ after pollination) at $25{ }^{\circ} \mathrm{C}$ on $0.6 \%$ agar plate in dark. Seed germination was evaluated daily during 0 to $7 \mathrm{~d}$. Seed having a radical length greater than 0.5 $\mathrm{cm}$ in length were counted as germinated seed. Each data point represents the mean \pm SD of triplicates of 50 seed.

weight and water content in L. fendleri seed development are similar to other plants such as castor (Chen et al., 2004; Greenwood and Bewley, 1982), Arabidopsis (Baud et al., 2002), Brassica oleracea (Demir and Balkaya, 2005; Gurusamy and Thiagarajan, 1998), and Brassica napus (Norton and Harris, 1975).

In our study, a mature desiccated $L$. fendelri seed weighed $\approx 0.66 \mathrm{mg}$ and contained $27.6 \%$ oil, comparable to previous reports (Dierig et al., 2001, 2006). The protein content of $23.6 \%$ was also comparable to the $22.1 \%$ reported (Carlson et al., 1990). Besides oil and protein, $\approx 54 \%$ of seed weight was other accumulated dry matter. It is reported that this includes $\approx 38 \%$ of gum (Wu and Abbott, 1999) and 12.8\% of crude fiber (Carlson et al., 1990).

To study changes in protein profile associated with seed development, we examined the temporal pattern of protein accumulation using SDS-PAGE. As shown in Figure 4, high-molecular-weight protein bands were prominent and the profile was stable during early development from Days 7 to 21 (Stages I to III). A major change occurred at the onset of maturation (Stage IV, 28 DAP), when the high-molecular-weight protein bands diminished and, concomitantly, low-molecularweight protein bands appeared. These lowmolecular-weight bands immediately became predominant and remained unchanged during the rest of seed development (Stages V to VII). It is likely that these low-molecularweight proteins are mature forms of storage proteins derived from their precursor proproteins of higher molecular weights through posttranslational cleavage process. Such a process has been demonstrated for various storage proteins during seed development, including $2 \mathrm{~S}$ albumins in castor (Ahn and Chen, 2007; Irwin et al., 1990), 2S napin (Muren et al., 1995), and 12S globulin (Rodin and Rask, 1990) in Brassica napus and 7S and $11 \mathrm{~S}$ protein in soybean (Sengupta et al., 1981). In addition, similar bands were shown in a protein fractionation study ( $\mathrm{Wu}$ and Hojilla-Evangelista, 2005), in which seed protein in $L$. fendleri was separated into water-soluble albumin, salt-soluble globulin, and alkali-soluble glutelin.

Seed vigor and viability were tested by germination experiments. As shown in Figure 5, seed did not germinate until 35 DAP. The failure of germination during early development may be the result of the lack of sufficient nutrients (Gurusamy and Thiagarajan, 1998). The germination percentage increased quickly from $47 \%$ at 35 DAP to a high of $95 \%$ at $42 \mathrm{DAP}$ after $7 \mathrm{~d}$ of incubation. Harrington has suggested that physiological maturity is the developmental stage at which seed reaches its maximum dry weight, achieves maximum viability and vigor, and begins to desiccate because nutrients are no longer entering the seed from the plant (Harrington, 1972). Our results show that, based on Harrington's description, L. fendleri reached physiological maturity at $\approx 42$ DAP when silique and seedcoat changed color and water content of whole seed had naturally fallen to $25 \%$. We observed that fully desiccated seed (Stage VII, 49 DAP) in which the moisture content had declined below 5\% slightly decreased germination percentage to $89 \%$, probably because of excessive drying affecting colloidal affinity for water (Harrington, 1918). Similar results were also reported in cauliflower (Gurusamy and Thiagarajan, 1998) and Brassica oleracea (Demir and Balkaya, 2005)

In conclusion, we have presented a series of seed studies, including size and color, weight and germination, and reserve synthesis and protein pattern in L. fendleri. Our results represent snapshots of comprehensive biological activities hardwired in seed development program. In addition, we have demonstrated an effective staging system in illustration of various morphological, physiological, and biochemical changes during seed development in L. fendleri. The staging system provides a framework for further studies on accumulation patterns of fatty acid components, protein species, and gene expression patterns, which are essential for developing and implementing a genetic engineering approach for crop improvement in L. fendleri.

\section{Literature Cited}

Abbott, T.P., Y. Victor Wu, K.D. Carlson, M.E. Slodki, and R. Kleiman. 1994. Isolation and preliminary characterization of Lesquerella fendleri gums from seed, presscake, and defatted meal. J. Agr. Food Chem. 42:16781685 .

Ahn, Y.J. and G.Q. Chen. 2007. Temporal and spatial expression of $2 \mathrm{~S}$ albumin in castor (Ricinus communis L.). J. Agr. Food Chem. 55:10043-10049.

Baud, S., J.P. Boutin, M. Miquel, L. Lepiniec, and C. Rochat. 2002. An integrated overview of seed development in Arabidopsis thaliana ecotype WS. Plant Physiol. Biochem. 40:151-160.

Carlson, K.D., A. Chaudhry, and M.O. Bagby. 1990. Analysis of oil and meal from Lesquerella 
fendleri seed. Journal of the American Oil Chemists' Society 67:438-442.

Caupin, H.J. 1997. Products from castor oil: Past, present, and future. Lipid Technologies and Applications, p. 787-795. In: Gunstone, F.D. and F.B. Padley (eds.). Marcel Dekker, New York, NY.

Chen, G.Q., X. He, L.P. Liao, and T.A. McKeon. 2004. 2S albumin gene expression in castor plant (Ricinus communis L.). Journal of the American Oil Chemists' Society 81:867-872.

Demir, E. and A. Balkaya. 2005. Seed development stages of kale (Brassic oleracea var. acephala L.) genotypes in Turkey. Horticulture Science (Prague) 32:147-153.

Dierig, D.A., A.M. Salywon, P.M. Tomasi, G.H. Dahlquist, and T.A. Isbell. 2006. Variation of seed oil composition in parent and S1 generations of Lesquerella fendleri (Brassicaceae). Ind. Crops Prod. 24:274-279.

Dierig, D.A., P.M. Tomasi, and G.H. Dahlquist. 2001 Registration of WCL-LY2 high oil Lesquerella fendleri germplasm. Crop Sci. 41:604-605.

Engeseth, N. and S. Stymne. 1996. Desaturation of oxygenated fatty acids in Lesquerella and other oil seeds. Planta 198:238-245.

Greenwood, J.S. and J.D. Bewley. 1982. Seed development in Ricinus communis (castor bean). I. Descriptive morphology. Can. J. Bot. 60:1751-1760.
Gurusamy, C. and C.P. Thiagarajan. (1998). The pattern of seed development and maturation in califlower (Brassica oleracea L. var. botrytis). Phyto-Annales Rei Botanicae. 38:259-268.

Harrington, G.T. 1918. Resistance of seeds to desiccation. J. Agr. Res. 14:525-532.

Harrington, J.F. 1972. Seed biology. Academic Press, New York, NY.

Harry-O'kuru, R.E., C.J. Carriere, and R.E. Wing. 1999. Rheology of modified Lesquerella gum. Ind. Crops Prod. 10:11-20.

Holser, R.A., C.J. Carriere, and T.P. Abbott. 2000. Rheological properties of Lesquerella gum fractions recovered by aqueous extraction. Ind. Crops Prod. 12:63-69.

Irwin, S.D., J.N. Keen, J.B.C. Findlay, and J.M Lord. 1990. The Ricinus communis $2 \mathrm{~S}$ albumin precursor: A single preproprotein may be processed into two different heterodimeric storage proteins. Mol. Gen. Genet. 222:400-408.

Mcllrath, W.J., Y.P. Abrol, and F. Heiligman 1963. Dehydration of seeds in intact tomato fruits. Science 142:1681-1682.

Muren, E., B. Ek, and L. Rask. 1995. Processing of the $2 \mathrm{~S}$ storage protein pronapin in Brassica napus and in transformed tobacco. Eur. J. Biochem. 227:316-321.

Norton, G. and J.F. Harris. 1975. Compositional changes in developing rape seed (Brassica napus L.). Planta 123:163-174.
Reed, D.W., D.C. Taylor, and P.S. Covello. 1997. Metabolism of hydroxy fatty acids in developing seeds in the genera Lesquerella (Brassicaceae) and Linum (Linaceae). Plant Physiol. 114:63-68.

Rodin, J. and L. Rask. 1990. The relationship between mature chains and their precursors of cruciferin, the $12 \mathrm{~S}$ storage protein of Brassica napus. Plant Sci. 70:57-63.

Sengupta, C., V. Deluca, D.S. Bailey, and D.P.S. Verma. 1981. Post-translational processing of $7 \mathrm{~S}$ and $11 \mathrm{~S}$ components of soybean storage proteins. Plant Mol. Biol. 1: 19-34.

Smith, C.R., Jr., T.L. Wilson, T.K. Miwa, H Zobel, R.L. Lohmar, and I.A. Wolff. 1961. Lesquerolic acid. A new hydroxy acid from Lesquerella seed oil. J. Org. Chem. 26:29032905.

Wu, Y.V. and T.P. Abbott. 1996. Enrichment of gum content from Lesquerella fendleri seed coat by air classification. Ind. Crops Prod. 5:47-51.

Wu, Y.V. and T.P. Abbott. 1999. Particle-size reduction in gum concentration. Cereal Foods World. 44:673-676.

Wu, Y.V. and M.P. Hojilla-Evangelista. 2005. Lesquerella fendleri protein fractionation and characterization. Journal of the American Oil Chemists' Society 82:53-56. 